\title{
Research Paper: Leisure Activity Preferences of Children and Adolescents With Cerebral Palsy in Iran and the Quality of Their Participation
}

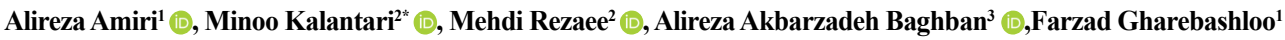 \\ 1. Physiotherapy Research Centre, School of Rehabilitation, Shahid Beheshti University of Medical Sciences, Tehran, Iran. \\ 2. Department of Occupational Therapy, School of Rehabilitation, Shahid Beheshti University of Medical Sciences, Tehran, Iran. \\ 3. Department of Biostatistics, Proteomics Research Centre, School of Allied Medical Sciences, Shahid Beheshti University of Medical Sciences, Tehran, Iran
}

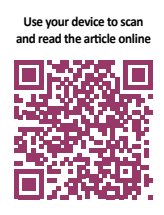

Citation Amiri A, Kalantari M, Rezaee M, Akbarzadeh Baghban A, Gharebashloo F. Leisure Activity Preferences of Children and Adolescents With Cerebral Palsy in Iran and the Quality of Their Participation. Iranian Rehabilitation Journal. 2020; 18(3):281-292. http://dx.doi.org/10.32598/irj.18.3.659.3

doil'http://dx.doi.org/10.32598/irj.18.3.659.3

Article info:

Received: 02 Oct 2019

Accepted: 15 Apr 2020

Available Online: 01 Sep 2020

Keywords:

Child, Adolescent, Cerebral palsy, Leisure activities

\section{A B S T RACT}

Objectives: To investigate whether Iranian children and adolescents with Cerebral Palsy (CP) participate in their preferred leisure activities.

Methods: A group of children and adolescents ( $\mathrm{n}=152 ; 59.2 \%$ male; aged 7-17 years; Mean \pm SD of age was $10.93 \pm 3.46$ years old $)$ diagnosed with $\mathrm{CP}$ (39.5\% hemiplegic; $28.9 \%$ quadriplegic; $31.6 \%$ diplegic) were selected to complete the children's assessment of participation and the enjoyment (CAPE) and Preference for Activities of Children (PAC) questionnaires.

Results: Recreational and social activities were the most preferred (PAC mean score $=2.13 \pm 0.40$; $2.08 \pm 0.40$, respectively), and active-physical activities were the least preferred (PAC mean score $=1.60 \pm 0.46)$. Preferences were strongly correlated with leisure participation $(\mathrm{P}<0.001)$, although there were still discrepancies between them. Adiscrepancy score was introduced, and skillbased activities demonstrated the highest discrepancy score (discrepancy mean score $=3.39 \pm 2.97$ ).

Discussion: Greater preferences for leisure activities are linked with a higher frequency of participation but, that does not necessarily mean that children and adolescents with $\mathrm{CP}$ always participate in their most preferred leisure activities. They sometimes cannot participate in their preferred leisure activities and sometimes participate in activities that they do not like. Occupational therapists are encouraged to consider these findings to design more effective plans to achieve improved participation outcomes.

* Corresponding Author:

Minoo Kalantari, PhD.

Address: Department of Occupational Therapy, School of Rehabilitation, Shahid Beheshti University of Medical Sciences, Tehran, Iran. Tel: +98 (912) 808658

E-mail:minookalantari@sbmu.ac.ir 


\section{Highlights}

- During their leisure time, children and adolescents with Cerebral Palsy (CP) prefer social and recreational activities the most.

- Active-physical activities are the least preferred leisure activities among children and adolescents with cerebral palsy.

- Preferences for leisure activities are influenced by the child factors (i.e. age, sex, cerebral palsy type, etc.).

- Greater preferences for leisure activities are linked with a higher frequency of participation.

- Sometimes, children and adolescents with cerebral palsy cannot participate in their preferred leisure activities.

- Sometimes, children and adolescents with cerebral palsy participate in leisure activities they do not like.

\section{Plain Language Summary}

Participation in leisure-time activities is a child's right and a vital part of the development of children and adolescents, yet those with Cerebral Palsy (CP) often experience restrictions to participate in leisure activities. $\mathrm{CP}$ is a motor and postural disorder that is caused by damage to the brain when it is still developing. Participation restriction can cause a variety of psychosocial problems for children and adolescents with CP and studying ways to alleviate it has received growing interest over the years. One of the central defining factors of leisure participation is leisure preference, which means a greater liking towards a leisure activity. Specifying leisure preferences of children and adolescents with $\mathrm{CP}$ and how they associate with their leisure participation could be valuable information helping us to alleviate their participation restrictions. In this study, we found out that social and recreational activities were the most preferred leisure activities whereas active-physical activities were the least preferred group of activities. We also found out how leisure preferences of children and adolescents differ based on the child's characteristics (i.e. age, sex, CP type, etc.). We observed that greater preferences for activities are linked with increasing participation, yet sometimes children and adolescents with CP cannot participate in their preferred activities and sometimes participate in activities they do not like. Considering these findings, occupational therapists and other health professionals can plot more effective therapeutic plans to alleviate restrictions to leisure participation of children and adolescents with $\mathrm{CP}$ and improve the quality of their leisure participation.

\section{Introduction}

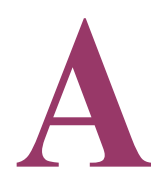

fundamental part of the development of children and youth, whether or not they have disabilities, is their participation in challenging and intrinsically motivating activities [1]. Participation in leisure activities provides opportunities for people with disabilities, just like people with typical development, to develop skills and promote their physical, mental, and social health [2]. Besides, participation in leisure-time activities promotes the child's health, well-being, sense of community membership, and quality of life [3-6]. According to the World Health Organization's International Classification of Functioning, Disability, and Health (ICF), participation is defined as the person's involvement in life situations [7]. Leisure activities are enjoyable voluntarily chosen activities that people do during their spare time, excluding self-care activities [2, 4, 8]. Gillian King described it as a child's involvement in the formal and informal everyday activities in all types of nonschool environments, including environments for play, sport, entertainment, learning, and religious expression [2].

Leisure participation for children and adolescents with disabilities, including those with Cerebral Palsy (CP) is often challenging [9]. Hence, their participation in leisure activitie is significantly less than their normal peers [1013]. The term $\mathrm{CP}$ describes a group of permanent disorders of the development of movement and posture, attributed to non-progressive disturbances in the developing brain, commonly accompanying secondary disturbances, activity limitations [14], and decreased quality of life [3, 15, 16]. Consequently, children and adolescents with CP face various physical, social, and attitudinal barriers that restrict the extent and quality of their leisure-time participation [5, 17]. Participation restrictions can cause social adjustment problems, feelings of loneliness, and mental health difficulties [18-20]. Therefore, investigations regarding leisure 
participation have received growing interest, especially ever since the World Health Organization [7] brought the concept of participation to the forefront in the ICF.

Leisure participation is influenced by a variety of personal and environmental factors. Age, gender, level of disability, environmental barriers, and several other factors are associated with leisure participation $[21,22]$. In the conceptual model of the factors affecting the recreation and leisure participation of children with disabilities, proposed by King et al. [2], activity preferences are demonstrated as one of the child factors that directly influence leisure-time participation. Preference lexically means a greater liking for one alternative over another [23]. In other words, preference refers to "what a child would like to do" [4] and also to the act of choosing between alternatives, the most satisfying ones [24]. Preference-based leisure participation promotes learning, knowledge of self, and a sense of mastery [25]. It has also been reported that participation in activities that the child himself prefers is a determinant of health [26]. Previous investigations also indicate that greater preference for certain types of leisure activities is associated with an increased rate of participation in those activities $[4,8$, 27-29]. Therefore, preferences play a pivotal role in both the literal and practical definition of leisure participation.

Up to now, leisure participation of children and adolescents with $\mathrm{CP}$ and its associated factors has been thoroughly investigated, yet few studies have described their preferences for leisure activities [4, 5, 24, 25]. Thus, the first objective of this study is to provide a better understanding of the leisure preferences of children and adolescents with $\mathrm{CP}$ and how they may contribute to their actual involvement in leisure activities.

Even though children and adolescents with disabilities may demonstrate having particular leisure preferences and that their preferences be associated with greater participation in certain types of activities, various obstacles may still restrict their participation in their preferred activities. That is, they sometimes prefer activities in which they cannot participate and sometimes participate in activities they do not prefer. To date, some studies have investigated the associations and discrepancies between leisure preferences and leisure participation of children and adolescents with CP [4, 24, 25, 28]. Still, no studies to our knowledge have provided any information regarding the leisure participation-preference congruence of Iranian children and adolescents with CP. As reviewed by Pashmdarfard et al. [30], there is a significant scarcity of information regarding leisure participation of CP children in Iran, and currently, few studies on this topic have never specified leisure preferences of $\mathrm{CP}$ children nor investigated the associations between leisure participation and leisure preferences. That is the case while studies regarding leisure participation and leisure preferences of children and adolescents of different cultural backgrounds around the world could be used for multicultural interventions meeting the needs of a variety of ethnic groups worldwide [2]. Furthermore, as clearly stated in the leisure participation model of $\mathrm{G}$. King et al. [2], information regarding cultural differences in preferences, or participation patterns, could contribute to the broad applicability of this highly acclaimed model. Thus the second objective of this study is to investigate the associations between leisure preferences and leisure participation of children and adolescents with CP in an Iranian population. In summary, the present article specifically aims to:

Specify leisure preferences of children and adolescents with $\mathrm{CP}$, Investigate correlations between leisure preferences and the intensity of leisure participation, and Investigate discrepancies between leisure preferences and the diversity of leisure participation.

\section{Methods}

\section{Study participants}

The study population consisted of children and adolescents with CP aged 7-17 years living in Bojnurd City, Iran. The sample size was estimated at 150 using Cochran's method. The identification data of 718 children and adolescents diagnosed with CP were obtained from the Social Welfare Organization and the Special Education Organization of the city of Bojnurd. Among them, 476 met the inclusion criteria, and a final sample of 163 individuals was selected as our sample using a systematic random sampling method. Individuals were included in this study if they were a resident of Bojnurd between 7 and 17 years of age diagnosed with CP by a neurologist, had an IQ score higher than 50 according to the Estimated Cognitive Levels (ECL) of the SPARCLE project [31], and agreed willingly to participate in the study. Children and adolescents who were unwilling to participate in the study or to complete the questionnaires, or did not answer to some questionnaire items were excluded from the study.

\section{Study measures}

Leisure preferences were assessed using the Preferences for Activities of Children (PAC) [32]. It is a similar measure to Children's Assessment of Participation and 
Enjoyment (CAPE) and rates preferences on a 3-point scale (1=Would not like to do at all, $2=$ Would sort of like to do, $3=$ Would really like to do) for 55 activities which fall into 5 categories (i.e. recreational, active-physical, social, skill-based and self-improvement activities). A higher mean indicates a higher preference for the activity category.

The CAPE consists of the same 55 activities and rates them with 'yes' or 'no' based on the fact that the child has performed them in the past four months. If performed, it then rates the intensity of the activity (how often) based on a 7-point scale from 1 (one time in the past 4 months) to 7 (once a day or more). It also consists of enjoyment, with whom, and where scores but only diversity and intensity scores of CAPE were used for this study. The validity and reliability of the Persian version of the CAPE have been tested on 164 children with disabilities between 7 and 17 years of age; the results indicated a good internal consistency ( $\alpha=0.86$ ) within the test domains, so the test was determined to be appropriate for the Iranian population [33]

The ECL of the participating children and adolescents was determined using the ECL form [34] which is part of the impairment form of the SPARCLE project. It is a parent-report measure that estimates the IQ of the child/adolescent according to the IQ classification of ICD 10. This measure classifies intellectual disability into three levels: (i) severe cognitive disability (IQ<50), (ii) mild cognitive disability $(50 \leq \mathrm{IQ}<70)$, and (iii) normal (70 $\leq \mathrm{IQ})$.

\section{Study procedure}

A cross-sectional study design was used. The data collection process took place in participants' homes. It started in March 2017 and ended in June 2017. Once written consent was obtained, a pediatric neurologist clinically examined the potential participant to verify their CP diagnosis and determined its type. The participating children and adolescents were then categorized into three groups based on their CP type: (i) spastic quadriplegia; (ii) spastic diplegia, and (iii) spastic hemiplegia. Demographic information, including the age and sex of the child, was then recorded. After, the child/adolescent's parent answered to ECL short form to determine the child/adolescent's ECL. To ensure that the participant is cognitively capable of completing the CAPE/PAC, children and adolescents with an IQ below 50 (according to ICD-10) were excluded from the study. Eligible children and adolescents then participated in the completion of the CAPE/ PAC questionnaire. According to the manual of CAPE/ PAC, children and adolescents who could not complete the questionnaires on their own, due to either physical disability or illiteracy, should take help from their parent or caregiver as their proxy. To ensure the accuracy of the data, information reported by children and adolescents was rechecked and confirmed by their parents.

\section{Statistical analysis}

Descriptive statistics were conducted to characterize leisure preferences among participants, categorized by their CP type and gender. The Kruskal-Wallis test was used to investigate differences in preferences among CP type groups. The Mann-Whitney $U$ test was used to compare activity preferences between genders. The intensity scores were used to investigate correlations between leisure preferences and leisure participation, through the Spearman test. All analyses were performed in SPSS version 16.0 (IBM Corporation, USA).

To analyze the discrepancy between participation and preferences, positive and negative discrepancy scores were calculated. To calculate the discrepancy scores, preference scores were dichotomized into 0 "Would not like to do at all," and 1 "Would sort of like to do," and "Would really like to do" then the discrepancy between the diversity of participation and the dichotomized preference score was calculated. A positive discrepancy score indicates that the dichotomized preference score is 1 while the diversity of participation as 0 , demonstrating that the child preferred the activity but had not performed it in the past 4 months. A negative discrepancy score indicates that the dichotomized preference score is 0 while the diversity score is 1 , implying that the child did not prefer the activity and nonetheless had performed it in the past 4 months. Positive and negative discrepancy scores of activities belonging to the same domain were then accumulated to finally attribute one positive and one negative discrepancy score to each domain for every participant. Bult et al. used a similar method [4].

Differences in discrepancy scores among CP type groups and between genders were analyzed by the Kruskal-Wallis and the Mann-Whitney U tests, respectively.

\section{Study Ethical consideration}

Ethical approval was granted from the Ethics Committee of Shahid Beheshti University of Medical Sciences (IR.SBMU.RETECH.REC.1396.641). Informed consent was obtained from all human adult participants and the parents or legal guardians of minors. 
Table 1. Participants' characteristics

\begin{tabular}{|c|c|c|c|}
\hline \multirow{2}{*}{\multicolumn{2}{|c|}{ Characteristics }} & \multicolumn{2}{|c|}{ Age (y) } \\
\hline & & No. (\%) & Mean士SD \\
\hline \multirow[b]{2}{*}{ Sex } & Girls & $62(40.8)$ & $10.61 \pm 3.43$ \\
\hline & Boys & $90(59.2)$ & $11.16 \pm 3.49$ \\
\hline \multirow{3}{*}{ CP type } & Hemiplegic & $60(39.5)$ & $11.27 \pm 3.50$ \\
\hline & Quadriplegic & $44(28.9)$ & $10.27 \pm 3.63$ \\
\hline & Diplegic & $48(31.6)$ & $11.13 \pm 3.25$ \\
\hline \multicolumn{2}{|c|}{ Total } & $152(100)$ & $10.93 \pm 3.46$ \\
\hline
\end{tabular}

SD: Standard Deviation; CP: Cerebral Palsy.

Iranian Rehabilitation Journa

\section{Results}

Participants' characteristics

Of 163 potential participants, 11 individuals were excluded according to the exclusion criteria, constituting a drop-out rate of $6.75 \%$. Their mean age was 10.93 years
$(\mathrm{SD}=3.46)$, and 90 participants were male. The characteristics of participants are presented in Table 1.

\section{Preference differences among types of $\mathrm{CP}$}

Recreational and social activities were the most preferred (recreational mean $=2.13, \mathrm{SD}=0.40$; social mean $=2.08$,

Table 2. Preference differences by CP type

\begin{tabular}{|c|c|c|c|c|c|c|}
\hline \multirow{2}{*}{ Domain } & \multirow{2}{*}{ CP Type } & \multirow{2}{*}{ PAC (Mean \pm SD) } & \multirow{2}{*}{$\mathbf{P}$} & \multicolumn{3}{|c|}{ Pairwise Comparisons (The Kruskal-Wallis Test) } \\
\hline & & & & Sample 1 - Sample 2 & Test Statistics & $\mathbf{P}$ \\
\hline \multirow{3}{*}{ Recreational } & Hemiplegic & $2.20 \pm 0.35$ & & Quadriplegia - Hemiplegia & 27.08 & 0.006 \\
\hline & Quadriplegic & $1.89 \pm 0.48$ & 0.000 & Quadriplegia-Diplegia & -35.84 & 0.000 \\
\hline & Diplegic & $2.27 \pm 0.25$ & & Hemiplegia - Diplegia & -8.75 & 0.908 \\
\hline \multirow{3}{*}{$\begin{array}{l}\text { Active- } \\
\text { physical }\end{array}$} & Hemiplegic & $1.69 \pm 0.46$ & & Quadriplegia-Hemiplegia & 28.93 & 0.003 \\
\hline & Quadriplegic & $1.41 \pm 0.41$ & 0.002 & Quadriplegia-Diplegia & -25.87 & 0.014 \\
\hline & Diplegic & $1.66 \pm 0.45$ & & Hemiplegia - Diplegia & 3.06 & 1.000 \\
\hline \multirow{3}{*}{ Social } & Hemiplegic & $2.16 \pm 0.34$ & & Quadriplegia-Hemiplegia & N/A & N/A \\
\hline & Quadriplegic & $1.95 \pm 0.44$ & 0.089 & Quadriplegia-Diplegia & N/A & $\mathrm{N} / \mathrm{A}$ \\
\hline & Diplegic & $2.10 \pm 0.39$ & & Hemiplegia - Diplegia & N/A & N/A \\
\hline \multirow{3}{*}{ Skill-based } & Hemiplegic & $1.81 \pm 0.45$ & & Quadriplegia - Hemiplegia & 19.99 & 0.065 \\
\hline & Quadriplegic & $1.59 \pm 0.40$ & 0.042 & Quadriplegia-Diplegia & -19.37 & 0.103 \\
\hline & Diplegic & $1.81 \pm 0.43$ & & Hemiplegia - Diplegia & 0.61 & 1.000 \\
\hline \multirow{3}{*}{$\begin{array}{c}\text { Self-i } \\
\text { mprovement }\end{array}$} & Hemiplegic & $1.76 \pm 0.42$ & & Quadriplegia-Hemiplegia & 24.89 & 0.013 \\
\hline & Quadriplegic & $1.50 \pm 0.38$ & 0.003 & Quadriplegia-Diplegia & -28.61 & 0.005 \\
\hline & Diplegic & $1.77 \pm 0.39$ & & Hemiplegia - Diplegia & -3.71 & 1.000 \\
\hline
\end{tabular}

PAC: Preference for Activities of Children; N/A: Not Applied.

Mranian Rehabilitation Journal 
Table 3. Gender differences in preferences

\begin{tabular}{|c|c|c|c|c|}
\hline \multirow{2}{*}{ Variables } & \multirow{2}{*}{ Group } & \multirow{2}{*}{ PAC (Mean $\pm S D)$} & \multicolumn{2}{|c|}{ Mann-Whitney Test Statistics } \\
\hline & & & Mann-Whitney U test & $\mathbf{P}$ \\
\hline \multirow{3}{*}{ Recreational } & Boys & $2.12 \pm 0.42$ & \multirow{3}{*}{2706.50} & \multirow{3}{*}{0.754} \\
\hline & & & & \\
\hline & Girls & $2.15 \pm 0.38$ & & \\
\hline \multirow{3}{*}{ Active-physical } & Boys & $1.67 \pm 0.47$ & \multirow{3}{*}{2128.00} & \multirow{3}{*}{0.013} \\
\hline & & & & \\
\hline & Girls & $1.49 \pm 0.41$ & & \\
\hline \multirow{3}{*}{ Social } & Boys & $2.06 \pm 0.44$ & \multirow{3}{*}{2702.50} & \multirow{3}{*}{0.742} \\
\hline & & & & \\
\hline & Girls & $2.11 \pm 0.33$ & & \\
\hline \multirow{3}{*}{ Skill-based } & Boys & $1.75 \pm 0.46$ & \multirow{3}{*}{2784.00} & \multirow{3}{*}{0.982} \\
\hline & & & & \\
\hline & Girls & $1.74 \pm 0.42$ & & \\
\hline \multirow{3}{*}{ Self-improvement } & Boys & $1.68 \pm 0.39$ & \multirow{3}{*}{2716.50} & \multirow{3}{*}{0.782} \\
\hline & & & & \\
\hline & Girls & $1.70 \pm 0.45$ & & \\
\hline
\end{tabular}

Iranian Rehabilitation Dourna

Table 4. Correlation between preferences and intensity of participation

\begin{tabular}{|c|c|c|c|}
\hline \multirow{2}{*}{ Domain } & \multicolumn{2}{|c|}{ Mean $\pm S D$} & \multirow{2}{*}{$\begin{array}{c}\text { P } \\
\text { Spearman Test }\end{array}$} \\
\hline & Preference Scores & Intensity of Participation & \\
\hline Recreational & $2.13 \pm 0.40$ & $2.63 \pm 1.21$ & 0.000 \\
\hline Active-physical & $1.60 \pm 0.46$ & $0.91 \pm 0.93$ & 0.000 \\
\hline Social & $2.08 \pm 0.40$ & $2.22 \pm 1.04$ & 0.000 \\
\hline Skill-based & $1.75 \pm 0.44$ & $0.90 \pm 0.87$ & 0.000 \\
\hline Self-improvement & $1.69 \pm 0.41$ & $1.03 \pm 0.97$ & 0.000 \\
\hline
\end{tabular}

Iranian Rehabilitation Dournal

$\mathrm{SD}=0.40$ ), and active-physical activities were the least preferred (mean=1.60, $\mathrm{SD}=0.46$ ). As displayed in Table 2, children with different $\mathrm{CP}$ types showed different preferences for all leisure domains, except for the social domain $(\mathrm{P}=0.089)$. Preference differences between children with hemiplegic and diplegic CP were not statistically significant. While children with hemiplegic and diplegic CP preferred recreational activities more than other domains; children with quadriplegic CP mostly preferred social activities. Of note, children and adolescents with quadriplegic $\mathrm{CP}$ had lower preference scores in all five domains compared to the other two groups.

\section{Gender differences in leisure preferences}

As illustrated in Table 3, activity preferences between genders showed no significant differences except in active-physical activities $(\mathrm{P}=0.013)$ for which boys demonstrated greater preferences. It is also noteworthy that in the active-physical domain, girls showed a greater preference for 'playing games' while boys preferred bicycling, in-line skating, or skateboarding more than other physical activities. Both genders preferred recreational and social activities more than in other domains. 


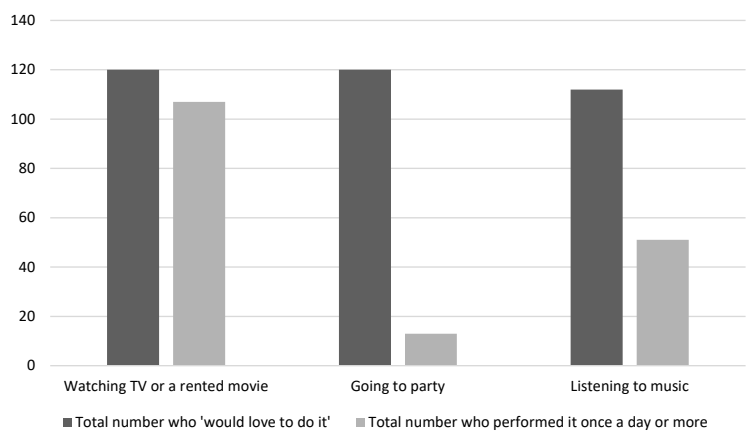

Iranian Rehabilitation Journa

Figure 1. Top 3 most preferred leisure activities

Correlation between preferences and actual participation in leisure activities

As presented in Table 4, the intensity of participation and activity preferences were strongly correlated in all domains $(\mathrm{P}<0.001)$.

Discrepancies between preferences and actual participation

Even though preferences for leisure activities and the frequency of participation were strongly correlated, through the analysis of activities individually, it was revealed that some activities, although highly preferred, are not performed, frequently. Figure 1 demonstrates the top three most preferred activities and the total number of participants who performed them once a day or more.

The significant proportion of the discrepancy between preferences and participation consisted of activities that the child/adolescent preferred but did not perform, compared to those that the child performed contrary to his or her preference. Skill-based, recreational, and activephysical domains had the highest discrepancy means, respectively. Further information regarding the discrepancies is shown in Table 5.
The difference in discrepancy scores among types of $\mathrm{CP}$, and between genders were also investigated. The analyses observable in Table 6 , show no statistically significant differences.

\section{Discussion}

The present study aimed to determine the preferences for leisure activities of children and adolescents with $\mathrm{CP}$ in Iran and to investigate the associations between their leisure activity preferences and their actual participation. To date, several studies have investigated different aspects of leisure participation of children and adolescents with $\mathrm{CP}$ in Iran while none has paid attention to their preferences [9-11, 13, 22, 30, 35-37]. In this regard, this study was unlike any other and could not be compared to the results of any studies reporting on an Iranian population.

This study demonstrated that children and adolescents with $\mathrm{CP}$ prefer to participate in a variety of activities in their leisure time, but mostly recreational and social activities. Although very few studies have investigated leisure preferences of children and adolescents with $\mathrm{CP}$, some studies have reported similar results, with recreational and social domains as their most preferred domains of activity [4, 24]. However, the least preferred activities in their findings were the self-improvement domain; while our results ranked that domain as the second least preferred. Physical activities were the least preferred domain in our study, which may reflect that children and adolescents with CP dislike doing activities that they are not good at. It might also imply that some modifications in the activity or the environment are required to make this domain as preferable as other leisure domains.

Children and adolescents with different types of $\mathrm{CP}$ showed different preferences in most domains. However,

Table 5. Discrepancy sum scores between preference and diversity of participation

\begin{tabular}{ccc}
\hline \multirow{2}{*}{ Domains } & \multicolumn{2}{c}{ Mean \pm SD } \\
\cline { 2 - 3 } & Positive Discrepancy Sum Scores & Negative Discrepancy Sum Scores \\
\hline Recreational & $3.32 \pm 2.30$ & $0.09 \pm 0.31$ \\
Active-physical & $2.96 \pm 3.50$ & $0.03 \pm 0.16$ \\
Social & $2.09 \pm 2.06$ & $0.07 \pm 0.30$ \\
Skill-based & $3.39 \pm 2.97$ & $0.03 \pm 0.16$ \\
Self-Improvement & $2.88 \pm 2.80$ & $0.04 \pm 0.19$ \\
\hline
\end{tabular}


Table 6. Discrepancy differences by Cerebral Palsy (CP) type and gender

\begin{tabular}{|c|c|c|c|c|c|}
\hline \multicolumn{2}{|c|}{ Domains Groups } & \multicolumn{2}{|c|}{ Positive Discrepancy Sum Scores } & \multicolumn{2}{|c|}{ Negative Discrepancy Sum Scores } \\
\hline & & Mean $\pm S D$ & $\mathbf{P}$ & Mean $\pm S D$ & $\mathbf{P}$ \\
\hline \multirow{6}{*}{ Recreational } & Hemiplegic CP & $3.97 \pm 2.84$ & \multirow{3}{*}{0.136} & $0.13 \pm 0.34$ & \multirow{3}{*}{0.238} \\
\hline & Quadriplegic CP & $2.66 \pm 1.49$ & & $0.05 \pm 0.21$ & \\
\hline & Diplegic CP & $3.13 \pm 1.96$ & & $0.08 \pm 0.34$ & \\
\hline & Girls & $3.40 \pm 2.49$ & \multirow{3}{*}{0.970} & $0.06 \pm 0.24$ & \multirow{3}{*}{0.435} \\
\hline & & & & & \\
\hline & Boys & $3.27 \pm 2.17$ & & $0.11(0.35)$ & \\
\hline \multirow{6}{*}{ Active-physical } & Hemiplegic CP & $3.73 \pm 4.00$ & \multirow{3}{*}{0.155} & $0.00 \pm 0.00$ & \multirow{3}{*}{0.263} \\
\hline & Quadriplegic CP & $2.27 \pm 2.76$ & & $0.05 \pm 0.21$ & \\
\hline & Diplegic CP & $2.62 \pm 3.32$ & & $0.04 \pm 0.20$ & \\
\hline & Girls & $2.66 \pm 3.65$ & \multirow{3}{*}{0.170} & $0.05 \pm 0.21$ & \multirow{3}{*}{0.160} \\
\hline & & & & & \\
\hline & Boys & $3.17 \pm 3.40$ & & $0.01 \pm 0.10$ & \\
\hline \multirow{6}{*}{ Social } & Hemiplegic CP & $2.38 \pm 2.46$ & \multirow{3}{*}{0.811} & $0.10 \pm 0.35$ & \multirow{3}{*}{0.430} \\
\hline & Quadriplegic CP & $1.86 \pm 1.69$ & & $0.02 \pm 0.15$ & \\
\hline & Diplegic CP & $1.92 \pm 1.79$ & & $0.08 \pm 0.34$ & \\
\hline & Girls & $2.10 \pm 2.33$ & \multirow{3}{*}{0.579} & $0.11 \pm 0.36$ & \multirow{3}{*}{0.108} \\
\hline & & & & & \\
\hline & Boys & $2.08 \pm 1.86$ & & $0.04 \pm 0.25$ & \\
\hline \multirow{6}{*}{ Skill-based } & Hemiplegic CP & $3.80 \pm 3.31$ & \multirow{3}{*}{0.469} & $0.02 \pm 0.12$ & \multirow{3}{*}{0.638} \\
\hline & Quadriplegic CP & $2.89 \pm 2.60$ & & $0.05 \pm 0.21$ & \\
\hline & Diplegic CP & $3.35 \pm 2.83$ & & $0.02 \pm 0.14$ & \\
\hline & Girls & $3.08 \pm 3.11$ & \multirow{3}{*}{0.182} & $0.05 \pm 0.21$ & \multirow{3}{*}{0.160} \\
\hline & & & & & \\
\hline & Boys & $3.61 \pm 2.87$ & & $0.01 \pm 0.10$ & \\
\hline \multirow{6}{*}{ Self-Improvement } & Hemiplegic CP & $3.33 \pm 3.22$ & \multirow{3}{*}{0.564} & $0.03 \pm 0.18$ & \multirow{3}{*}{0.948} \\
\hline & Quadriplegic CP & $2.66 \pm 2.35$ & & $0.05 \pm 0.21$ & \\
\hline & Diplegic CP & $2.52 \pm 2.59$ & & $0.04 \pm 0.20$ & \\
\hline & Girls & $2.63 \pm 2.95$ & \multirow{3}{*}{0.122} & $0.03 \pm 0.17$ & \multirow{3}{*}{0.705} \\
\hline & & & & & \\
\hline & Boys & $3.06 \pm 2.70$ & & $0.04 \pm 0.20$ & \\
\hline
\end{tabular}

analyses found no significant differences in social activities, possibly because the performance of these activities depends on motor functions to a lesser extent. Interestingly, preferences of children with hemiplegic and those of children with diplegic CP were not significantly different in any domain. It could probably suggest that they face similar participation barriers and facilitators, resulting in similar preferences for activities. Further, the quadriplegic group had significantly fewer preferences for leisure activities compared to the other two groups which are in agreement with other reports, conceivably indicating that lower gross motor functions can be followed by decreased activity participation [24, 37, 38]. No studies to our knowledge had investigated preference differences among different types of $\mathrm{CP}$ before. 
Another finding of this study demonstrated that differences in activity preferences between girls and boys were not significant, except in active-physical activities. Congruent with gender expectations, boys had higher tendencies toward active-physical activities in our study. Likewise, Shikako-Thomas et al. investigated gender differences in preferences. Interestingly, contrary to our results, they reported significant gender differences in all domains, except in the active-physical domain. Other similar studies reflect that females have greater preferences for skill-based activities [24, 29, 39].

It was also found that preference for all leisure domains and their intensity of participation was strongly correlated; however, our findings also demonstrated that children and adolescents with CP do not necessarily perform their most preferred activities frequently. While it is seemingly related to their disabilities and activity limitations, it might also be partially related to factors other than the child's disabilities, especially when we look at the findings of Bult et al. [4], who reported no significant differences between children with and without disabilities regarding preference-based leisure participation. Furthermore, the preference for "going to party" despite being one of the top three most preferred activities in our study, was not correlated with its intensity of participation $(\mathrm{P}=0.079)$, probably as a result of numerous social and attitudinal barriers families face to take their children with disabilities to parties. Similar to our study, Majnemer et al. [24] examined the correlations between PAC and CAPE scores. Compared to our results, they reported strong correlations between preference and intensity of participation in recreational and skill-based domains, but not in other domains.

Regarding the discrepancies found between leisure preferences and leisure participation, skill-based, recreational, and active-physical domains had the highest discrepancy scores. These results are relatively congruent with those of Bult et al. [4] reporting active-physical and skill-based activities as their top two domains with the highest discrepancy scores among children with disabilities. It is also noteworthy that the discrepancy scores of Bult et al. were generally higher than those of ours, and that they interestingly found no significant differences in discrepancy scores between children with and without disabilities. The international study of Imms et al. [25] also found that activephysical and skill-based domains had the highest preference-participation discrepancy. Congruent with our results, the discrepancies related to "doing non-preferred activities" were generally lower than discrepancies related to "not doing preferred activities" in their study.
This study had some limitations. Given the nature of the analyses, the causes of the observed differences and correlations are not known for sure. Moreover, participants might have taken part in some activities such as 'doing water sports' and 'doing snow sports' during the past summer or winter, yet the CAPE/PAC questionnaires are completed based on leisure activities of the past 4 months which makes the outcomes partially season-dependent and it might cause some inaccuracies in the interpretation of results. Despite the above limitations, this study was the first of its kind reporting on a population in Iran. It also provides valuable information to help reduce the paucity of data concerning the leisure preferences of children with $\mathrm{CP}$ and identifies areas needing further examination. Furthermore, the findings of our study could be clinically valuable for occupational therapists who seek to plan interventions aimed at promoting leisure participation in this particular population.

Furthermore, the research could seek to answer the following questions: What are the predictors of leisure preferences for children with CP? What are the causes that children do not perform some highly preferred activities frequently? What cultural factors shape the leisure preferences and leisure participation patterns of Iranian children and adolescents? What possible interventions could help children and adolescents with CP participate in their preferred activities more frequently?

\section{Conclusions}

Children and adolescents with $\mathrm{CP}$ prefer doing social and recreational activities more than other leisure-time activities. Leisure preferences generally differ based on the child's gender and CP type. Even though preferences are strongly correlated with actual participation in all leisure domains, children and adolescents with CP do not necessarily participate in their most preferred activities frequently. They sometimes do not participate in the activities they prefer and sometimes participate in some activities they do not like. It is known that participation as the ultimate goal of rehabilitation cannot be achieved solely through intensive motor rehabilitation [36] and other factors affecting the participation should also be accounted for. The findings of this research article provide a better understanding of how leisure preferences of children and adolescents with $\mathrm{CP}$ associate with their leisure participation. Such information could help occupational therapists and other health professionals to design more effective rehabilitation plans to achieve improved participation outcomes. Furthermore, the information presented in this article could be used for multicultural studies of preference-participation patterns and also contribute to the broad applicability of G. King's Model [2]. 


\section{Ethical Considerations}

\section{Compliance with ethical guidelines}

The Ethics Committee of Shahid Beheshti University of Medical Sciences (IR.SBMU.RETECH.REC.1396.641) approved this paper. Informed consent was obtained from all adult participants and from the parents or legal guardians of minors.

\section{Funding}

This research did not receive any grant from funding agencies in the public, commercial, or non-profit sectors.

\section{Authors' contributions}

All authors equally contributed to preparing this article; Supervision, Minoo Kalantari.

\section{Conflict of interest}

The authors report no conflicts of interest.

\section{References}

[1] Larson RW. Toward a psychology of positive youth development. The American Psychologist. 2000; 55(1):170-83. [DOI:10.1037/0003-066X.55.1.170] [PMID]

[2] King G, Law M, King S, Rosenbaum P, Kertoy MK, Young NL. A conceptual model of the factors affecting the recreation and leisure participation of children with disabilities. Physical \& Occupational Therapy in Pediatrics. 2003; 23(1):63-90. [DOI:10.1080/J006v23n01_05] [PMID]

[3] Dahan-Oliel N, Shikako-Thomas K, Majnemer A. Quality of life and leisure participation in children with neurodevelopmental disabilities: A thematic analysis of the literature. Quality of Life Research. 2012; 21(3):427-39. [DOI:10.1007/ s11136-011-0063-9] [PMID]

[4] Bult MK, Verschuren O, Lindeman E, Jongmans MJ, Ketelaar M. Do children participate in the activities they prefer? A comparison of children and youth with and without physical disabilities. Clinical Rehabilitation. 2014; 28(4):38896. [DOI:10.1177/0269215513504314] [PMID]

[5] King G, Imms C, Palisano R, Majnemer A, Chiarello L, Orlin M, et al. Geographical patterns in the recreation and leisure participation of children and youth with cerebral palsy: A CAPE international collaborative network study. Developmental Neurorehabilitation. 2013; 16(3):196-206. [D OI:10.3109/17518423.2013.773102] [PMID]

[6] Shikako-Thomas K, Law M, Kolehmainen N, Ketelaar M, Ketelaar M, Bult M. Promoting leisure participation as part of health and well-being in children and youth with cer- ebral palsy. Journal of Child Neurology. 2014; 29(8):1125-33 [DOI:10.1177/0883073814533422] [PMID]

[7] World Health Organization. International classification of functioning, disability, and health: Children \& youth version: ICF-CY. Geneva: WHO; 2007. https://apps.who.int/iris/handle/10665/43737

[8] Majnemer A, Shevell M, Law M, Birnbaum R, Chilingaryan G, Rosenbaum P, et al. Participation and enjoyment of leisure activities in school-aged children with cerebral palsy. Developmental Medicine and Child Neurology. 2008; 50(10):751-8. [DOI:10.1111/j.1469-8749.2008.03068.x] [PMID]

[9] Amiri A, Kalantari M, Rezaee M, Akbarzadeh Baghban A. Correlation between mother-child relationship and participation of children and adolescents with cerebral palsy in leisure time activities. Iranian Rehabilitation Journal. 2018; 16(2):203-15. [DOI:10.32598/irj.16.2.203]

[10] Mehraban AH, Hasani M, Amini M. The comparison of participation in school-aged cerebral palsy children and normal peers: A preliminary study. Iranian Journal of Pediatrics. 2016; 26(3):e5303. [DOI:10.5812/ijp.5303] [PMID] [PMCID]

[11] Rostam Zadeh O, Amini M, Hasani Mehraban A. [Comparison of participation of children with cerebral palsy aged 4 to 6 in occupa-tions with normal peers (Persian)]. Journal of Rehabilitation. 2016; 17(3):192-9. [DOI:10.21859/jrehab-1703192]

[12] Hassani M, Hasani Mehraban A, Aliabadi F, Taghizadeh G. [Comparison of participation between children with cerebral palsy and typically developing peers 8-14 years old in leisure activities (Persian)]. Journal of Modern Rehabilitation. 2013; 7(1):63-9. http://mrj.tums.ac.ir/article-1-10-en.html

[13] Pashmdarfard M, Amini M. Comparing participation of iranian children with cerebral palsy in life activities with participation of typically developing children. Journal of Modern Rehabilitation. 2018; 12(2):97-104. https://jmr.tums.ac.ir/index.php/jmr/ article/view/162

[14] Rosenbaum P, Paneth N, Leviton A, Goldstein M, Bax M, Damiano D, et al. A report: The definition and classification of cerebral palsy April 2006. Developmental Medicine and Child Neurology. 2007; 49(s109):8-14. [PMID]

[15] Wu J, Zhang J, Hong Y. Quality of life of primary caregivers of children with cerebral palsy: A comparison between mother and grandmother caregivers in Anhui province of China. Child: Care, Health and Development. 2017; 43(5):718-24. [DOI:10.1111/ cch.12464] [PMID]

[16] Dalvand H, Dehghan L, Hosseini SA, Feizi A, Kalantari M. Comparison of health-related quality of life in mothers of children with spina bifida and cerebral palsy. International Journal of Pediatrics. 2017; 5(9):5677-85. [DOI: 10.22038/ IJP.2017.23670.2000]

[17] Baker K, Donelly M. The social experiences of children with disability and the influence of environment: A framework for intervention. Disability \& Society. 2001; 16(1):71-85. [DOI:10.1080/713662029]

[18] Blum RW, Resnick MD, Nelson R, Germaine AS. Family and peer issues among adolescents with spina bifida and cerebral palsy. Pediatrics. 1991; 88(2):280-5. [PMID]

[19] Cadman D, Boyle M, Szatmari P, Offord DR. Chronic illness, disability, and mental and social well-being: Findings of the Ontario child health study. Pediatrics. 1987; 79(5):805-13. [PMID] 
[20] King GA, Specht JA, Schultz I, Warr-Leeper G, Redekop $\mathrm{W}$, Risebrough N. Social skills training for withdrawn unpopular children with physical disabilities: A preliminary evaluation. Rehabilitation Psychology. 1997; 42(1):47-60. [DOI:10.1037/0090-5550.42.1.47]

[21] Shikako-Thomas K, Majnemer A, Law M, Lach L. Determinants of participation in leisure activities in children and youth with cerebral palsy: Systematic review. Physical \& Occupational Therapy in Pediatrics. 2008; 28(2):155-69. [DOI:10.1080/01942630802031834] [PMID]

[22] Amini M, Saneii SH, Pashmdarfard M. Factors affecting social participation of Iranian children with cerebral palsy. Occupational Therapy in Health Care. 2018; 32(3):290-305. [DOI: 10.1080/07380577.2018.1497820] [PMID]

[23] Weiner ESC, Simpson JA. The Oxford English dictionary. Oxford: Oxford University Press; 2004. [DOI:10.1111/j.00791636.2004.00140.x]

[24] Majnemer A, Shikako-Thomas K, Chokron N, Law M, Shevell M, Chilingaryan G, et al. Leisure activity preferences for 6- to 12-year-old children with cerebral palsy. Developmental Medicine and Child Neurology. 2010; 52(2):167-73. [DOI:10.1111/j.1469-8749.2009.03393.x] [PMID]

[25] Imms C, King G, Majnemer A, Avery L, Chiarello L, Palisano $\mathrm{R}$, et al. Leisure participation-preference congruence of children with cerebral palsy: A children's assessment of participation and enjoyment international network descriptive study. Developmental Medicine and Child Neurology. 2017; 59(4):380-7. [DOI:10.1111/dmcn.13302] [PMID]

[26] Townsend E. Enabling occupation: An occupational therapy perspective. Vancouver: Canadian Association of Occupa; 2012.

[27] Garton AF, Pratt C. Leisure activities of adolescent school students: Predictors of participation and interest. Journal of Adolescence. 1991; 14(3):305-21. [DOI:10.1016/01401971(91)90023-K] [PMID]

[28] Shikako-Thomas K, Shevell M, Lach L, Law M, Schmitz N, Poulin C, et al. Are you doing what you want to do? Leisure preferences of adolescents with cerebral palsy. Developmental Neurorehabilitation. 2015; 18(4):234-40. [DOI:10.3109/17518423. 2013.794166] [PMID]

[29] Law M, King G, King S, Kertoy M, Hurley P, Rosenbaum $P$, et al. Patterns of participation in recreational and leisure activities among children with complex physical disabilities. Developmental Medicine and Child Neurology. 2006; 48(5):337-42. [DOI:10.1017/S0012162206000740] [PMID]

[30] Pashmdarfard M, Amini M, Mehraban AH. Participation of Iranian cerebral palsy children in life areas: A systematic review article. Iranian Journal of Child Neurology. 2017; 11(1):1-12. [PMID] [PMCID]

[31] Colver A, SPARCLE group. Study protocol: SPARCLEA multi-centre European study of the relationship of environment to participation and quality of life in children with cerebral palsy. BMC Public Health. 2006; 6:105-14. [DOI:10.1186/1471-2458-6-105] [PMID] [PMCID]

[32] King GA, Law M, King S, Hurley P, Hanna S, Kertoy M, et al. Children's Assessment of Participation and Enjoyment (CAPE) and Preferences for Activities of Children (PAC). New York: PsychCorp; 2000.
[33] Amirian SR, Rezaee M, Pashazadeh Azari Z, Tabatabaee SM. [Validity and reliability of children's assessment of participation and enjoyment for people with disability aged 7-17 years old (Persian)]. Cientific Journal of Rehabilitation Medicine. 2015; 4(1):26-32. [DOI: 10.22037/JRM.2015.1100005]

[34] Gunel MK, Mutlu A, Tarsuslu T, Livanelioglu A. Relationship among the Manual Ability Classification System (MACS), the Gross Motor Function Classification System (GMFCS), and the functional status (WeeFIM) in children with spastic cerebral palsy. European Journal of Pediatrics. 2009; 168(4):477-85. [DOI:10.1007/s00431-008-0775-1] [PMID]

[35] Pashmdarfard M, BADV RS. The impact of manual ability level on participation of children with cerebral palsy in life areas: A cross-sectional study. Iranian Journal of Child Neurology. 2019; 13(3):83-91. https://journals.sbmu.ac.ir/ijcn/ article/view/18040

[36] Rostamzadeh O, Hasani Mehraban A, Amini M. [Comparison of participation of 4-6 years-old children with cerebral palsy in area of occupations according to gross motor function level (Persian)]. Scientific Journal of Rehabilitation Medicine. 2019; 7(4):191-7. [DOI: 10.22037/JRM.2018.110575.1380]

[37] Amiri A, Kalantari M, Rezaee M, Akbarzade Baghban A. Participation in leisure-time activities and the role of individual factors in children and adolescents with cerebral palsy. International Journal of Therapy and Rehabilitation 2019; 26(5):1-6. [DOI:10.12968/ijtr.2018.0075]

[38] Nobakht Z, Rassafiani M, Rezasoltani P, Sahaf R, Yazdani F. Environmental barriers to social participation of children with cerebral palsy in Tehran. Iranian Rehabilitation Journal. 2013; 11(Special Issue):40-5. http://irj.uswr.ac.ir/article1-355-en.html

[39] Engel-Yeger B, Jarus T. Cultural and gender effects on Israeli children's preferences for activities. Canadian Journal Of Occupational Therapy. 2008; 75(3):139-48. [DOI:10.1177/00084 1740807500305] [PMID] 
This Page Intentionally Left Blank 